\title{
The aorta in repaired tetralogy of Fallot: A potential source of late danger?
}

\author{
Joseph B. Clark, MD
}

From the Division of Pediatric Cardiac Surgery, Department of Pediatrics, Penn State Children's Hospital, Hershey, Pa.

Disclosures: Author has nothing to disclose with regard to commercial support.

Received for publication Sept 12, 2018; accepted for publication Sept 13, 2018.

Address for reprints: Joseph B. Clark, MD, Division of Pediatric Cardiac Surgery, Department of Pediatrics, Penn State Children's Hospital, 500 University Dr H085, Hershey, PA 17033 (E-mail: jclark7@ pennstatehealth.psu. edu).

J Thorac Cardiovasc Surg 2018;156:2250

$0022-5223 / \$ 36.00$

Copyright $₫ 2018$ Published by Elsevier Inc. on behalf of The American Association for Thoracic Surgery https://doi.org/10.1016/j.jtcvs.2018.09.044

With this novel and innovative study, Schafer and colleagues ${ }^{1}$ have turned a spotlight on the overlooked (presumptively healthy) left side of the heart in repaired tetralogy of Fallot (TOF). Although emphasis has been paid to the management of the right ventricular outflow tract in TOF, this report calls attention to the potentially hostile nature of the aorta in this disease. Using advanced magnetic resonance imaging techniques, the anatomy and physiology of the thoracic aorta was characterized in TOF children with prior repair during infancy. Although the cohort size was modest, the findings of the study appear compelling. Despite having normal aortic dimensions, the repaired TOF patients demonstrated increased aortic stiffness, wall shear stress, and pathologic flow characteristics. Because these conditions are common in other aortic diseases associated with dissection and rupture, these findings spark cause for concern.

Historically, when repair of TOF was delayed beyond infancy, enlarged aortic dimensions persisted, likely due to prolonged increased flow across the aortic valve. Optimal management of the dilated aorta in repaired TOF was uncertain, with a perception that the enlarged TOF aorta was safer than in other diseases. This belief was supported by the literature, which failed to show much in the way of aortic complications, with just a handful of reported cases of aortic dissection in TOF. ${ }^{2}$ In these rare circumstances, dissection typically occurred in the setting of a massively enlarged aorta. Furthermore, one large population study could appreciate no increased incidence of aortic dissection in TOF patients. $^{2}$

With the evolution toward infant repair of TOF, a presumably fortunate consequence was realized. As corroborated by this report by Schafer and colleagues, ${ }^{1}$ early repair of TOF leads to normalization of aortic dimensions during childhood. In the absence of vessel enlargement, one may suppose that the risk of aortic morbidity would be mitigated. However, according to the present findings, that happy scenario may not be the case: Favorable aortic

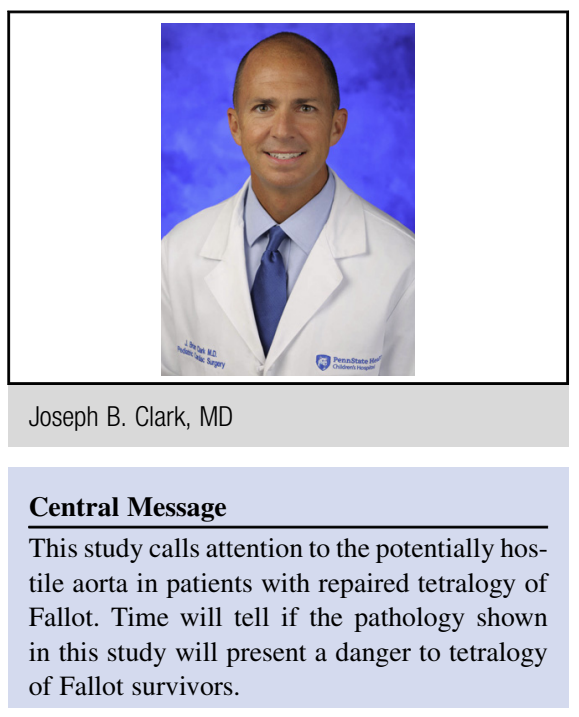

See Article page 2239 .

dimensions in TOF do not appear to be associated with favorable aortic physiology. In this study, aortic stiffness remained a progressive element of TOF pathology. If excess stiffness represents substrate for future dilatation, the normal aortic dimensions observed in young TOF patients may not persist.

What remains to be seen is whether this aortopathy will eventually translate into adverse clinical outcomes in this sizable population. It may take decades for this quiescent disease to manifest as an appreciable hazard. Will dissection occur in the setting of the nondilated, noncompliant aorta? In this study, there was a trend toward elevated diastolic blood pressure in the TOF patients. Will diastolic hypertension become a source of morbidity? As Schafer and colleagues ${ }^{1}$ suggest, the ill effects of this disease may not be limited to the aorta. The left ventricle may strain under the burden of the poorly compliant vasculature. Will the aortic valve suffer? As this population ages, time will tell whether the threatening aortic pathology revealed in this study will represent a significant source of late danger to TOF survivors.

\section{References}

1. Schafer M, Browne LP, Morgan GJ, Barker AJ, Fonseca B, Ivy DD, et al. Reduced proximal aortic compliance and elevated wall shear stress after early repair of tetralogy of Fallot. J Thorac Cardiovasc Surg. 2018;156:2239-49.

2. Frischhertz BP, Shamszad P, Pedroza C, Milewicz DM, Morris SA. Thoracic aortic dissection and rupture in conotruncal cardiac defects: a population-based study. Int J Cardiol. 2015;184:521-7. 